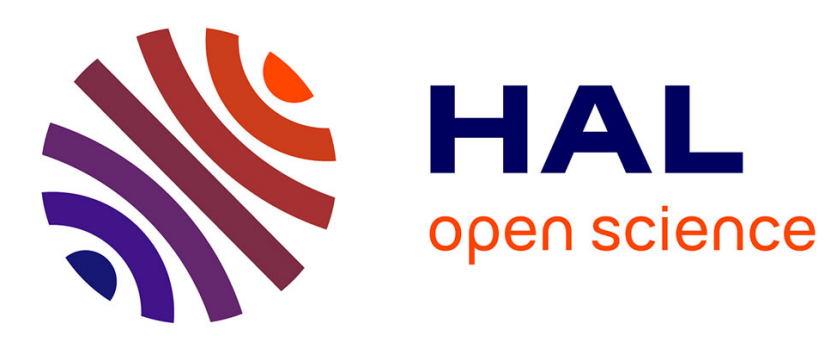

\title{
Stereoselective differences in the cytochrome P450-dependent dealkylation and demethylenation of -methyl-benzodioxolyl-butanamine (MBDB, Eden) enantiomers
}

\author{
Markus R. Meyer, Frank T. Peters, Hans H. Maurer
}

\section{To cite this version:}

Markus R. Meyer, Frank T. Peters, Hans H. Maurer. Stereoselective differences in the cytochrome P450-dependent dealkylation and demethylenation of -methyl-benzodioxolyl-butanamine (MBDB, Eden) enantiomers. Biochemical Pharmacology, 2009, 77 (11), pp.1725. 10.1016/j.bcp.2009.03.001 . hal-00493501

\section{HAL Id: hal-00493501 \\ https://hal.science/hal-00493501}

Submitted on 19 Jun 2010

HAL is a multi-disciplinary open access archive for the deposit and dissemination of scientific research documents, whether they are published or not. The documents may come from teaching and research institutions in France or abroad, or from public or private research centers.
L'archive ouverte pluridisciplinaire HAL, est destinée au dépôt et à la diffusion de documents scientifiques de niveau recherche, publiés ou non, émanant des établissements d'enseignement et de recherche français ou étrangers, des laboratoires publics ou privés. 


\section{Accepted Manuscript}

Title: Stereoselective differences in the cytochrome P450-dependent dealkylation and demethylenation of $\mathrm{N}$-methyl-benzodioxolyl-butanamine (MBDB, Eden) enantiomers

Authors: Markus R. Meyer, Frank T. Peters, Hans H. Maurer

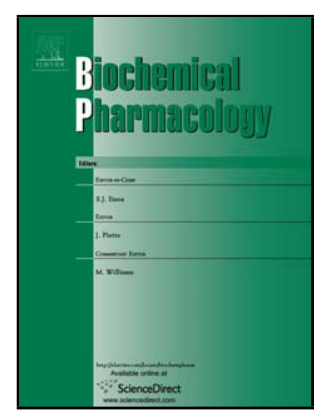

PII: S0006-2952(09)00155-5

DOI: doi:10.1016/j.bcp.2009.03.001

Reference: BCP 10110

To appear in: $\quad B C P$

Received date: 21-1-2009

Revised date: 25-2-2009

Accepted date: $\quad 3-3-2009$

Please cite this article as: Meyer MR, Peters FT, Maurer HH, Stereoselective differences in the cytochrome P450-dependent dealkylation and demethylenation of $\mathrm{N}$-methylbenzodioxolyl-butanamine (MBDB, Eden) enantiomers, Biochemical Pharmacology (2008), doi:10.1016/j.bcp.2009.03.001

This is a PDF file of an unedited manuscript that has been accepted for publication. As a service to our customers we are providing this early version of the manuscript. The manuscript will undergo copyediting, typesetting, and review of the resulting proof before it is published in its final form. Please note that during the production process errors may be discovered which could affect the content, and all legal disclaimers that apply to the journal pertain. 

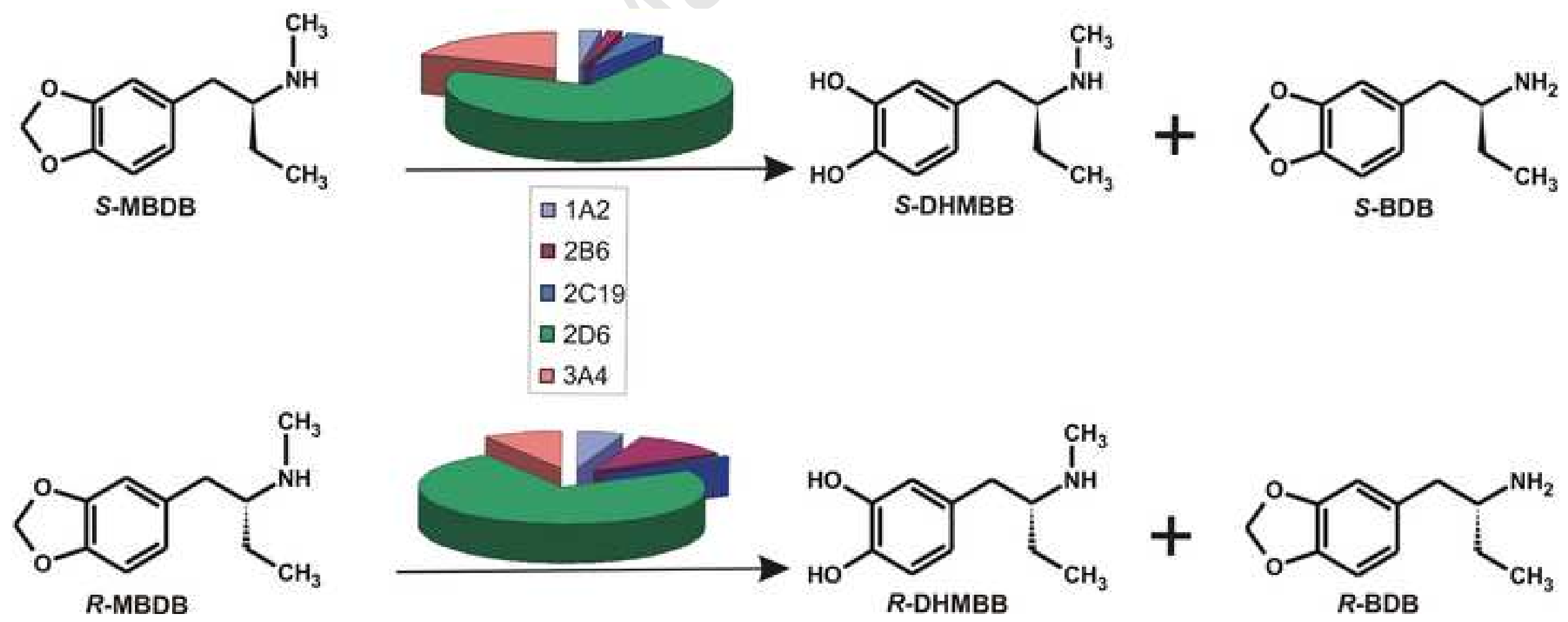
Stereoselective differences in the cytochrome P450-dependent dealkylation and demethylenation of $N$-methyl-benzodioxolylbutanamine (MBDB, Eden) enantiomers

\author{
Markus R. Meyer ${ }^{1}$, Frank T. Peters ${ }^{1,2}$, and Hans H. Maurer ${ }^{1 *}$ \\ ${ }^{1}$ Department of Experimental and Clinical Toxicology, Institute of Experimental and Clinical \\ Pharmacology and Toxicology, Saarland University, D-66421 Homburg (Saar), Germany \\ ${ }^{2}$ Institute of Forensic Medicine, Friedrich Schiller University, D-07740 Jena, Germany
}

\footnotetext{
* Corresponding author. Phone: +49-6841-16-26050; fax: +49-6841-16-26051.

E-mail address: hans.maurer@uks.eu (H.H. Maurer)
} 


\section{ABSTRACT}

In the present study, cytochrome P450 isozymes (P450) involved in the stereoselective metabolism of the designer drug $N$-methyl-benzodioxolyl-butanamine (MBDB, Eden) were identified for the first time. Demethylenation and $N$-demethylation of racemic MBDB as well as its single enantiomers were investigated using cDNA expressed insect cell microsomes. After incubation of MBDB, the two resulting main metabolites 1,2-dihydroxy-4-[2(methylamino)butyl]benzene (DHMBB) and benzodioxolyl-butanamine (BDB) were separated and quantified by achiral gas chromatography-mass spectrometry after chiral derivatization with $S$-heptafluorobutyrylprolyl chloride. Dealkylation was mainly catalyzed by CYP2B6 and CYP2C19, demethylenation was additionally catalyzed by CYP1A2, CYP2D6, and CYP3A4. The most abundant isozymes after in vitro-in vivo correlation using the relative activity factor approach are CYP2B6 for $N$-dealkylation and CYP2D6 for demethylenation the second step being the most relevant. In addition, inhibition studies towards MBDB biotransformation using the CYP2D6 selective inhibitor quinidine confirmed the dominant role of this polymorphic isozyme in total MBDB metabolism. In general, at low substrate concentrations the $S$-enantiomer is metabolized at a higher rate foremost by CYP2C19. These findings are in line with results previously reported for the corresponding ring substituted amphetamines 3,4-methylenedioxy-methamphetamine and 3,4methylenedioxy-ethylamphetamine. In conclusion, the main enzyme responsible for MBDB metabolism after in vitro-in vivo correlation is CYP2D6, whereas CYP2C19 is the most enantioselective.

Keywords: MBDB, amphetamines, enantiomers, CYP, enzyme kinetic, inhibition 


\section{Introduction}

Besides 3,4-methylenedioxy-methamphetamine (MDMA, Ecstasy) and 3,4-methylenedioxyethylamphetamine (MDEA, Eve), another methylenedioxy compound, the $\alpha$-ethyl homologue of MDMA, $N$-methyl-benzodioxolyl-butanamine (MBDB, Eden) has appeared on the illicit drug market. Compared to MDMA and MDEA, the data currently available for MBDB concerning metabolism and toxicity are very limited. As reported by Van Aerts et al. [1], the understanding of the toxicological and pharmacological actions and prediction of the risks of consuming MBDB is harder than for MDMA/MDEA. From the pharmacological point of view, MBDB induces interpersonal communication, has MDMA-like stimulant effects and produces euphoria albeit to a lesser extent than MDMA [2]. MBDB is able to increase the concentration of dopamine, serotonin, and noradrenalin but to a minor extent than MDMA or MDEA. In general, MBDB and MDMA have similar properties which was also shown in animal drug discrimination tests $[3,4]$. Therefore, both are members of the same drug class called "entactogen" [5]. Concerning differences between $R$ - and $S$-MBDB, the $S$-enantiomer is more active in the matter of re-uptake inhibition in hippocampal samples [6] and more potent than the same oral dose of $R$-MBDB [1]. Furthermore, MDMA has been found to substitute in $S$-MBDB trained rats [7]. Johnson et al. suggested similar neurotoxic effects of MBDB and MDMA [8]. In the case of MDMA, its main metabolite 4dihydroxymethamphetamine (DHMA) is easily oxidized to its corresponding quinones which can form adducts with glutathione and other thiol-containing compounds [9-11]. Recently, such adducts have been implicated in MDMA neurotoxicity [12,13].

In vivo metabolism of MBDB is comparable to MDMA/MDEA (Fig.1). In phase-I, it is dealkylated to its active metabolite 3,4-methylenedioxybutanamin (BDB) and demethylenated to the corresponding dihydroxy compound 1,2-dihydroxy-4-[2-(methylamino)butyl]benzene (DHMBB) followed by conjugation in phase-II [14-17].

Since in vitro and in vivo metabolism of some ring substituted amphetamines (RSA) was shown to be more or less enantioselective [18-23], elucidating this phenomenon is important 
for the toxicological and pharmacological point of view. Concerning the most popular RSA

MDMA, several studies have shown that there is a metabolic preference for the $S$-enantiomer [18-23] and that this difference is at least partially attributable to cytochrome P450 isozymes (P450) [24-27]. MDEA was also investigated for that matter and studies revealed also a preference for the $S$-enantiomer which can explain its enantioselective elimination $[26,28,29]$. In the case of MBDB, the data currently available give no idea whether the $S$-form of this RSA is also metabolized preferably by $\mathrm{P} 450$ isoforms. Neither in vivo nor in vitro studies are available concerning the CYP-dependent metabolism of MBDB enantiomers. Solely, one study using racemic MBDB and CYP inhibition in pooled human liver microsomes is available, indicating CYP2D6, CYP3A4, and CYP1A2 being involved in its biotransformation [17].

Therefore, the aim of the presented study was to obtain enantioselective enzyme kinetic data of MBDB $N$-demethylation and demethylenation by the ten P450s most relevant in human drug metabolism.

\section{Materials and Methods}

\subsection{Chemicals and reagents}

Racemic hydrochloride of MBDB was obtained from Lipomed (Bad Saeckingen, Germany) and racemic DHMBB hydrochloride from ReseaChem (Burgdorf, Switzerland). Methanolic solution $(100 \mathrm{mg} / \mathrm{L})$ of racemic BDB- $d_{2}$ was obtained from Promochem (Wesel, Germany). Sodium bicarbonate was purchased from Fluka (Steinheim, Germany); NADP ${ }^{+}$from Biomol (Hamburg, Germany), isocitrate, isocitrate dehydrogenase, sodium metabisulfite $\left(\mathrm{Na}_{2} \mathrm{~S}_{2} \mathrm{O}_{5}\right)$ from Carl Roth (Karlsruhe, Germany), and 3,4-dihydroxybenzylamine (DHBA) from Sigma (Taufkirchen, Germany). Water was purified in the authors' lab using a Millipore filtration unit. All other chemicals and reagents were obtained from Merck (Darmstadt, Germany). The following microsomes were from BD Gentest (Woburn, MA, USA) and delivered by NatuTec 
(Frankfurt/Main, Germany): baculovirus-infected insect cell microsomes (Supersomes; ICM)

containing $1 \mathrm{nmol} / \mathrm{mL}$ human cDNA-expressed CYP1A2, CYP2A6, CYP2B6, CYP2C8, CYP2C9, CYP2C19, CYP2D6, and CYP3A4 or $2 \mathrm{nmol} / \mathrm{mL}$ CYP2E1 and CYP3A5; wildtype baculovirus-infected ICM (control Supersomes), and pooled human liver microsomes (pHLM $20 \mathrm{mg}$ microsomal protein/mL, $400 \mathrm{pmol}$ total P450/mg protein). After delivery, the microsomes were thawed at $37^{\circ} \mathrm{C}$, aliquoted, shock-frozen in liquid nitrogen and stored at $80^{\circ} \mathrm{C}$ until use. All chemicals were of analytical grade or the highest purity available. Single MBDB enantiomers were obtained in the authors' lab through enantioseparation of racemic MBDB as described below and elsewhere [24]. The derivatization reagent $S$ heptafluorobutyrylprolyl chloride $(S$-HFBPCl) was synthesized in the authors' laboratory according to [30].

\subsection{Isolation of single enantiomers}

Racemic MBDB was separated using a Hewlett Packard Series 1050 semi-preparative HPLC system consisting of a pump and a variable wavelength detector $(\lambda=285 \mathrm{~nm})$ which was coupled to an Advantec SF 2120 Super Fraction collector. The stationary phase was a Merck Hibar HPLC ChiraDex column $(250 \times 10 \mathrm{~mm}, 5 \mu \mathrm{m})$. The mobile phase consisted of $85 \%$ mobile phase $\mathrm{A}$ ( $0.1 \mathrm{M}$ ammonium acetate buffer adjusted to $\mathrm{pH} 7.0$ with acetic acid), and 15\% mobile phase B (acetonitrile 49.5\%, methanol 49.5\%, and triethylamine 1\%), flow rate 2 $\mathrm{mL} / \mathrm{min}$. The HPLC column was constantly tempered at $15^{\circ} \mathrm{C}$ using a refrigerator.

MBDB was separated in aliquots $(250 \mu \mathrm{L})$ of an aqueous stock solution $(1 \mathrm{mg} / \mathrm{mL}, 50 \mathrm{mg}$ in total). The fractions were collected and checked for optical purity by gas chromatographymass spectrometry (GC-MS) as described in detail under sample preparation. The respective enantiomer fractions were adjusted to $\mathrm{pH} 12$ with sodium hydroxide and extracted three times with ethyl acetate $(150 \mathrm{~mL})$. The combined extracts were dried using magnesium sulfate. Afterwards they were concentrated to a volume of approximately $1 \mathrm{~mL}$ under reduced 
pressure. Finally, the amount and purity of the MBDB enantiomers were checked as described in detail under sample preparation.

\subsection{Microsomal incubations}

Incubation mixtures (final volume: $50 \mu \mathrm{L}$ ) consisted of $90 \mathrm{mmol} / \mathrm{L}$ phosphate buffer $(\mathrm{pH} 7.4)$, $5 \mathrm{mmol} / \mathrm{L} \quad \mathrm{MgCl}_{2}, \quad 5 \mathrm{mmol} / \mathrm{L}$ isocitrate, $1.2 \mathrm{mmol} / \mathrm{L} \quad \mathrm{NADP}^{+}, \quad 0.5 \mathrm{U} / \mathrm{mL}$ isocitrate dehydrogenase, $200 \mathrm{U} / \mathrm{mL}$ superoxide dismutase and substrate at $37^{\circ} \mathrm{C}$. The substrate was added after dilution of a $25 \mathrm{mmol} / \mathrm{L}$ aqueous stock solution in the above-mentioned phosphate buffer. Reactions were started by addition of ice-cold microsomes and terminated with $5 \mu \mathrm{L}$ of $60 \%(\mathrm{w} / \mathrm{w})$ perchloric acid.

\subsection{Initial screening studies}

Incubations were performed with $25 \mu \mathrm{mol} / \mathrm{L} \quad R, S$-MBDB, $R$-MBDB, or $S$-MBDB and $50 \mathrm{pmol} / \mathrm{mL}$ CYP1A2, CYP2A6, CYP2B6, CYP2C8, CYP2C9, CYP2C19, CYP2D6, CYP2E1, CYP3A4, or CYP3A5 for $30 \mathrm{~min}$. For incubations with CYP2A6 or CYP2C9, phosphate buffer was replaced with $45 \mathrm{mmol} / \mathrm{L}$ or $90 \mathrm{mmol} / \mathrm{L}$ Tris buffer, respectively, according to the Gentest manual. Furthermore, HLM $(0.5 \mathrm{mg} / \mathrm{ml})$ were incubated for $30 \mathrm{~min}$ at a substrate concentration of $10 \mu \mathrm{mol} / \mathrm{L}$.

\subsection{Kinetic studies}

Kinetic constants of $N$-demethylation (expressed as BDB formation) or demethylenation (expressed as DHMBB formation) were derived from incubations with an incubation time of $1 \mathrm{~min}$ for CYP2D6 and $10 \mathrm{~min}$ for CYP1A2, 2B6, 2C19, and 3A4 and a P450 concentration of $50 \mathrm{pmol} / \mathrm{mL}$.

Calculation of enzyme kinetic constants was similar to previously published calculations [24,31]. Briefly, the Michaelis-Menten equation (equation 1) was used to calculate apparent $\mathrm{K}_{\mathrm{m}}$ and $\mathrm{V}_{\max }$ values for single-enzyme systems. Eadie-Hofstee plots were used to check for 
biphasic kinetics. If the Eadie-Hofstee plot indicated biphasic kinetics, eq 1 and the

alternative equation 2 for a two-enzyme model [32] were applied to the respective data. For equation $2, \mathrm{CL}_{\mathrm{int}, 2}$ represents the intrinsic clearance or $\mathrm{V}_{\mathrm{max}} / \mathrm{K}_{\mathrm{m}}$ of the low affinity component [32]. If equation 2 was found to fit the data significantly better ( $F$ test, $\mathrm{P}<0.05$ ), biphasic kinetics were assumed.

$$
\begin{gathered}
V=\frac{V_{\max } \times[S]}{K_{m}+[S]} \\
V=\frac{V_{\max , 1} \times[S]}{K_{m, 1}+[S]}+C L_{\mathrm{int}, 2} \times[S]
\end{gathered}
$$

The relative activity factor (RAF) approach [33-35] was used to account for differences in functional levels of redox partners between the two enzyme sources. The turnover rates (TR) of CYP2C19 [probe substrate (PS) $S$-mephenytoin], CYP2D6 (PS bufuralol), CYP2B6 (PS 7ethoxy-4-trifluoromethylcoumarin), CYP1A2 (PS phenacetin), and CYP3A4 (PS testosterone) in ICM and HLM were taken from the supplier's data sheets. The RAFs were calculated according to equation 3 .

$$
R A F_{\text {enzyme }}=\frac{T R_{P S} \text { in } \mathrm{HLM}[\mathrm{pmol} / \mathrm{min} / \mathrm{mg} \text { protein }]}{T R_{P S} \text { in ICM }[\mathrm{pmol} / \mathrm{min} / \mathrm{mg} \text { protein }]}
$$

The enzyme velocities $V_{\text {enyzme }}$ (see equation 1) for the respective metabolic reactions were calculated at different substrate concentrations and were then multiplied with the corresponding RAF leading to a value, which is defined as 'contribution'. The $V_{\max }$ and the $\mathrm{K}_{\mathrm{m}}$ values (equation 1) were obtained from the incubations with cDNA-expressed P450s.

$$
\text { contribution }_{\text {enzyme }}=R A F_{\text {enzyme }} \times V_{\text {enzyme }}
$$


The corrected activities (contributions), the percentages of net clearance by a particular P450 at a certain substrate concentration, can be calculated according to equation 5 :

$$
\text { clearance }_{\text {enzzme }}[\%]=\frac{\text { contribution }_{\text {enyzme }}}{\sum \text { contribution }_{\text {enzyme }}} \times 100
$$

\subsection{Chemical inhibition studies}

The effect of $3 \mu \mathrm{mol} / \mathrm{L}$ quinidine (CYP2D6 inhibitor) on DHMBB formation was assessed in incubations containing $0.5 \mathrm{mg}$ HLM protein $/ \mathrm{mL}$ and $1 \mu \mathrm{mol} / \mathrm{L}$ or $5 \mu \mathrm{mol} / \mathrm{L} R, S$-MBDB, $R$ MBDB, or $S$-MBDB ( $=6$ each). Control incubations $(\mathrm{n}=6)$ contained none of these chemical inhibitors. Significance of inhibition was tested by one-tailed unpaired t-tests using GraphPad Prism 3.02 software.

\subsection{Sample preparation}

After termination, the incubation mixtures were centrifuged and $30 \mu \mathrm{L}$ of the supernatants were transferred to $1.5-\mathrm{mL}$ reaction caps and diluted with $200 \mu \mathrm{L}$ aqueous carbonate buffer (35 g/L sodium bicarbonate and $15 \mathrm{~g} / \mathrm{L}$ sodium carbonate, $\mathrm{pH}$ 9) containing the respective internal standard (IS) racemic BDB- $d_{2}$ and DHBA $\left(0.02 \mathrm{ng} / \mathrm{mL}\right.$, each) and $3 \% \mathrm{Na}_{2} \mathrm{~S}_{2} \mathrm{O}_{5}$ and $3 \%$ EDTA-Na (250 mmol/L each) for preservation of the dihydroxy compounds.

Derivatization was performed according to [22], with slight modifications: after adding $30 \mu \mathrm{L}$ derivatization reagent $(0.1 \mathrm{~mol} / \mathrm{L} S$-HFBPCl in dichloromethane), the reaction vials were sealed and left on a rotary shaker at ambient temperature for $30 \mathrm{~min}$. After addition of $50 \mu \mathrm{L}$ cyclohexane to the reaction vials, they were resealed, and placed on a rotary shaker for 5 min. After phase separation by centrifugation (10000 $g$ for $1 \mathrm{~min})$, the cyclohexane phase was transferred to autosampler vials. Aliquots of $3 \mu \mathrm{L}$ were injected into the GC-MS.

\subsection{Enantioselective GC-NICI-MS quantification}


The samples were analyzed by an Agilent Technologies (AT) 6890 Series GC system combined with an AT 5973 network mass selective detector, an AT 7683 series injector, and an AT enhanced Chem Station G1701CA, version C.00.00 21-Dec-1999. For detection of $R, S$-BDB and $R, S$-BDB- $d_{2}$, the GC conditions were as follows: splitless injection mode; column, 5\% phenyl methyl siloxane (HP-5MS; $30 \mathrm{mx} 0.25 \mathrm{~mm}$ (i.d.); $250 \mathrm{~nm}$ film thickness); injection port temperature, $280^{\circ} \mathrm{C}$; carrier gas, helium; flow rate, $1 \mathrm{~mL} / \mathrm{min}$; column temperature, $180^{\circ} \mathrm{C}$ increased to $218^{\circ} \mathrm{C}$ at $50^{\circ} \mathrm{C} / \mathrm{min}$, to $230^{\circ} \mathrm{C}$ at $4{ }^{\circ} \mathrm{C} / \mathrm{min}$, and to $325^{\circ} \mathrm{C}$ at $50^{\circ} \mathrm{C} / \mathrm{min}$. The negative-ion chemical ionization (NICI)-MS conditions were as follows: transfer line heater, $280^{\circ} \mathrm{C}$; NICI, methane $(2 \mathrm{~mL} / \mathrm{min})$; source temperature, $150^{\circ} \mathrm{C}$; solvent delay, $3.5 \mathrm{~min}$; selected-ion monitoring (SIM) mode with the following ions: $\mathrm{m} / \mathrm{z} 446$ for $\mathrm{BDB}$ and 448 for $\mathrm{BDB}-\mathrm{d}_{2}$.

For detection of DHMBB and DHBA, the GC and NICI-MS conditions were modified as follows: column temperature, $180^{\circ} \mathrm{C}$ increased to $278^{\circ} \mathrm{C}$ at $50^{\circ} \mathrm{C} / \mathrm{min}$ to $299^{\circ} \mathrm{C}$ at $2^{\circ} \mathrm{C} / \mathrm{min}$, and to $325^{\circ} \mathrm{C}$ at $50^{\circ} \mathrm{C} / \mathrm{min}$. Solvent delay, $3.5 \mathrm{~min}$; SIM mode with the following ions: $\mathrm{m} / \mathrm{z}$ 780 for DHMBB and 430 for DHBA.

$\mathrm{BDB}$ and $\mathrm{DMBB}$ enantiomers were quantified by comparison of their peak-area ratios (enantiomers of analyte vs corresponding enantiomer of the IS) to calibration curves in which the peak-area ratios of enriched calibrators had been plotted vs their concentrations $(0.01,0.5$, $5.0,10 \mu \mathrm{mol} / \mathrm{L})$ using a weighted $(1 / x)$ least-squares linear regression model.

\section{Results}

\subsection{Semi-preparative separation of $R, S-M B D B$}

Fifty mg of racemic MBDB-HCl were separated under the described conditions. As the chiral HPLC method did not provide a satisfying purity and separation of the enantiomers, the above described separation and extraction procedure was performed twice. Purity check of the 
isolated enantiomers by GC-MS indicated high optical purities of $S$-MBDB $(97 \%)$ and $R$ MBDB (98\%). The yield was approximately $40 \%$ or $10 \mathrm{mg}$ per enantiomer.

\subsection{Enantioselective GC-NICI-MS quantification}

The mass fragmentograms shown in Fig. 2 demonstrate that the modified GC-MS conditions applied for analysis of DHMBB and BDB enantiomers provided sufficient separation. The chosen target ions were selective for the analytes under these conditions as proven with blank samples (control microsomes without substrate and IS) and zero samples (control microsomes without substrate, but with IS). The method showed sufficient linearity in a range of 0.01 to $10 \mu \mathrm{mol} / \mathrm{L}$ DHMBB or BDB $\left(\mathrm{r}^{2}=0.98-0.99\right)$.

\subsection{Initial activity screening}

$\mathrm{N}$-demethylation of racemic MBDB and its enantiomers was catalyzed by CYP2D6, CYP2B6, CYP2C19, CYP2E1, and CYP3A4. Demethylenation of MBDB and its enantiomers was catalyzed by CYP1A2, CYP2B6, CYP2C19, CYP2D6, and CYP3A4. After incubation of HLM at a concentration of $10 \mu \mathrm{mol} / \mathrm{L}$ racemic MBDB, DHMBB $(0.15 \mu \mathrm{g} / \mathrm{mL})$ and BDB $(0.07 \mu \mathrm{g} / \mathrm{mL})$ were formed indicating DHMBB to be the main metabolite.

\subsection{Kinetic studies}

The kinetic parameters could not be determined for all P450 capable of catalyzing the monitored metabolic reactions, because the activity of CYP2D6, CYP2E1 and CYP3A4 with respect to the $N$-demethylation was too low. The same was true for CYP2C19 catalyzed demethylenation of $R$-MBDB in racemic MBDB. The $\mathrm{K}_{\mathrm{m}}$ and $\mathrm{V}_{\max }$ values for the other P450s are listed in Table 1. The data for CYP2B6, and CYP2C19 ( $N$-demethylation) and CYP1A2, CYP2D6, CYP2C19, and CYP2B6, and CYP3A4 for $R$-MBDB (demethylenation) followed the expected classical hyperbolic Michaelis-Menten kinetics as shown in Fig. 3 A-D. In contrast, the Eadie-Hofstee plots (Fig. 6) of CYP2B6 for S-MBDB and CYP3A4 for racemic 
MBDB and $S$-MBDB (demethylenation) clearly indicated biphasic kinetics, which was

statistically confirmed (F-test, $\mathrm{p}<0.05$ ). Hence, the respective kinetic parameters were estimated by fitting the data into equation 2 for a biphasic kinetic. The second enzyme component is represented by $\mathrm{CL}_{\text {int, }, 2} \times[\mathrm{S}]$. The corresponding $\mathrm{V}_{\max 1} / \mathrm{K}_{\mathrm{m} 1}$ values are presented in Table 2. Fig. 4 shows plots of the percentages of net clearance as calculated from the RAFcorrected kinetic data versus substrate concentrations up to $10 \mu \mathrm{mol} / \mathrm{L}$. The data for total metabolite formation of $S$-MBDB, racemic MBDB, and $R$-MBDB are shown in panels A-C, respectively. At low substrate concentrations ( $1 \mu \mathrm{mol} / \mathrm{L})$, MBDB biotransformation is predominantly catalyzed by CYP2D6 with percentages of net clearance of $98 \%$ in the case of $S$-MBDB to $80 \%$ in the case of $R$-MBDB. Whereas, monitoring only the $N$-demethylation, CYP2B6 is the most important isozyme with a contribution of approximately $90 \%$. At high substrate concentrations (up to $10 \mu \mathrm{mol} / \mathrm{L}$ ), the relevance of CYP2D6 in total biotransformation decreases and the other isozymes become increasingly important, namely CYP3A4 in the case of $S$-MBDB, CYP2B6 in the case of racemic MBDB and CYP1A2/2B6 in the case of $R$-MBDB.

Marked enantioselectivity $\left(\mathrm{k}_{\mathrm{m}(R-\mathrm{MDMA}}\right) / \mathrm{k}_{\mathrm{m}(S \text {-MDMA })}>1.5$ or $\left.<0.5\right)$ was observed for CYP2C19, CYP2D6, and CYP3A4 for demethylenation. $N$-Demethylation seems not to be enantioselective in the case of $\mathrm{MBDB}$, whereas incubating racemic MBDB, maximum turnover rate $\left(\mathrm{V}_{\max }, \mathrm{CYP} 2 \mathrm{C} 19\right)$ of $S$-MBDB is nearly four times higher than $\mathrm{V}_{\max }$ of $R$ MBDB.

\subsection{Chemical inhibition studies}

To confirm the role of CYP2D6 in the most important step in MBDB metabolism which leads to the potentially toxic metabolite DHMBB, inhibition experiments were performed using pHLM, with the chemical inhibitor quinidine at a concentration according to the literature [36]. These experiments were performed at a substrate concentration representing concentrations expected in recreational users, namely $5 \mu \mathrm{mol} / \mathrm{L}$ to account for the 
concentration dependence of the involvement of individual P450s in MBDB demethylenation.

\section{Discussion}

Since only one study [17] is available using inhibition studies in pHLM to investigate the CYP-dependent metabolism of at least racemic MDMA, indicating CYP2D6, CYP3A4, and CYP1A2 being involved, this work does not account for the chirality of MBDB and the different in vivo metabolism of the two enantiomers. Furthermore, not all relevant $\mathrm{P} 450$ isoforms were considered due to a lack of specific inhibitors. The study presented here is the first providing enantioselective enzyme kinetic data of $\mathrm{N}$-demethylation and demethylenation of MBDB by the ten recombinant P450s, which are the most relevant in human drug metabolism. Among these enzymes was CYP2C19 which is known to be one of the five most abundant P450s involved in xenobiotic metabolism [37], which had so far not been considered in studies on MBDB metabolism.

The experiments were performed with racemic MBDB as present in clandestine tablets as well as single MBDB enantiomers to check whether certain P450s specifically metabolize certain enantiomers and whether the enantiomers influence each others' metabolism.

Various buffers and buffer concentrations as well as organic modifiers were tested for semipreparative isolation of the single enantiomers for these experiments. The best result in enantiomer separation was achieved with the mobile phase composition described in the Materials and Methods section but the phosphate buffer turned out to be problematic in the following isolation of the enantiomers. The final products were obtained in solution and quantified according to a modified previously published method for MDMA/MDEA enantiomers [22]. Despite rather low recoveries ( $\sim 40 \%$ per enantiomer), the isolated amounts were sufficient for further kinetic studies. 
The described quantification method according to [22] was modified to be applicable for the

presented kinetic studies. It is based on the derivatization of analyte enantiomers to diastereomers using an optically pure derivatization reagent. The diastereomeric derivatives can then be separated on an achiral GC column. In the present study, the amount of derivatization reagent had to be increased to achieve a reliable and reproducible (triple) derivatization of the DHMBB enantiomers. In addition, the oven temperature program, the run-time and the ions monitored in SIM had to be modified to allow separation and detection of BDB and the triple derivatives of the dihydroxy compounds, DHMBB and DHBA (Fig. 2). According to the supplier's advice, the incubation conditions chosen in the initial screening experiment are applicable for checking the general involvement of particular P450 enzymes. Because of the very low activity of CYP2D6, CYP2E1 and CYP3A4 with respect to the $\mathrm{N}$ demethylation and the CYP2C19 catalyzed demethylenation of $R$-MBDB in racemic MBDB only the other P450s which had shown activity in the initial screening could be characterized with respect to their kinetic profiles. Resulting curves are presented in Fig. 3 A-D. Duration and protein content of all incubations in these studies were within the linear range of metabolite formation (data not shown). Less than $20 \%$ of substrate was metabolized in all incubations with exception of the lowest substrate concentrations. $K_{m}$ and $V_{\max }$ values of the isozymes are presented in Table 1. Fig. 4 shows plots of the percentages of net clearance as calculated from the RAF corrected kinetic data versus substrate concentrations up to 10 $\mu \mathrm{mol} / \mathrm{L}$. The data for total metabolite formation after incubation of $S$-MBDB, racemic MBDB and $R$-MBDB are shown in panels A-C, respectively.

As already discussed for MDMA in our previous paper [24], there are inherent differences in the $\mathrm{K}_{\mathrm{m}}$ and $\mathrm{V}_{\max }$ values of the single enantiomer kinetics vs. the values of racemic MBDB in incubations with racemic MBDB. $R$ - and $S$-MBDB are competitors for the limited number of active sites in the incubation mixture. Each binding site can only transform one molecule at a time, either $R$-MBDB or $S$-MBDB. Hence, at saturation, approximately half of the active sites are busy transforming $R$-MBDB while the other half is busy transforming $S$-MBDB. In 
incubations of single enantiomers, however, all active sites are available for one enantiomer.

This explains the higher $V_{\max }$ values of the single enantiomer kinetics. The differences of the $\mathrm{K}_{\mathrm{m}}$ values can be explained in the same way. This coherence is considerably distinctive in the case of CYP2C19. Determination of kinetic data after incubation of racemic MBDB for $R$ MBDB is not possible because only a very small amount of $R$-DHMBB is formed throughout this enzymatic reaction resulting from a much higher affinity of $S$-MBDB for CYP2C19.

CYP2D6 turned out to be the isozyme with the highest affinity towards racemic MBDB and its enantiomers (Table 2). In addition, there is a generally higher affinity towards $S$-MBDB than $R$-MBDB concerning all involved isozymes. The obvious difference in the $\mathrm{K}_{\mathrm{m}}$ values of racemic MBDB and the respective enantiomers might be caused by interactions of $R$ - and $S$ MBDB in incubations of the racemate.

Common methods of calculating the net clearance are based on the assumption that substrate concentrations are lower than $10 \%$ of $\mathrm{K}_{\mathrm{m}}$ of the respective isozymes [34,38]. As described in one of our previous publication [24] this calculation is critical if the isozymes involved in the metabolic reaction have a very low $\mathrm{K}_{\mathrm{m}}$ value which is considerably below expected plasma concentrations. In the present study, $K_{m}$ values of $\leq 1 \mu \mathrm{mol} / \mathrm{L}$ were found for MBDB demethylenation by CYP2D6. These were below expected plasma concentrations of MBDB, which should usually be in the range of $1-5 \mu \mathrm{mol} / \mathrm{L}$ (207-1035 $\mu \mathrm{g} / \mathrm{L})$, as MBDB is consumed in the same or slightly higher dosage than MDMA, but can reach $6 \mu \mathrm{mol} / \mathrm{L}$ and higher in severe intoxications $[39,40]$. In the present study, we chose to calculate the percentages of net clearance for substrate concentrations ranging from 1 to $10 \mu \mathrm{mol} / \mathrm{L}$ (Fig. 4) to model the involvement of the studied P450s over the relevant concentration range. At low substrate concentrations $(1 \mu \mathrm{mol} / \mathrm{L})$, MBDB biotransformation was predominantly catalyzed by CYP2D6 (from 98 to $80 \%$ ). Whereas, monitoring only the $N$-demethylation, CYP2B6 is clearly the most abundant isoform. Also, at high substrate concentrations (up to $10 \mu \mathrm{mol} / \mathrm{L}$ ), the relevance of CYP2D6 in total biotransformation decreased and the other isozymes became 
increasingly important, namely CYP3A4 in the case of $S$-MBDB, CYP2B6 in the case of racemic $\mathrm{MBDB}$ and $\mathrm{CYP} 1 \mathrm{~A} 2 / 2 \mathrm{~B} 6$ in the case of $R$-MBDB.

To take a look at the inhibition studies, the demethylenation was inhibited significantly by quinidine at a substrate concentration of $5 \mu \mathrm{mol} / \mathrm{L}$ (Fig. 5). This is in line with the calculated percentages of net clearance as shown in Fig. 4.

This importance of CYP2D6 is critical from the toxicological point of view, because this isozymes can be inhibited by quite a number of different xenobiotics, e.g. MDMA which is known to be a mechanism-based inhibitor of this isozyme [41]. This means that in case of coingestion, the metabolism of MBDB might be considerably reduced. Moreover, due to structural and metabolic similarities between MBDB and MDMA, MBDB should also be a mechanism based inhibitor of CYP2D6 what additionally increases the risk of any kind of coingestion, but this has to be proven experimentally.

Marked enantioselectivity $\left(\mathrm{k}_{\mathrm{m}(R-\mathrm{MDMA})} / \mathrm{k}_{\mathrm{m}(S-\mathrm{MDMA})}>1.5\right.$ or $\left.<0.5\right)$ was observed for CYP2C19, CYP2D6, and CYP3A4 for demethylenation. $N$-Demethylation seems not to be enantioselective in the case of MBDB, whereas incubating racemic MBDB, maximum turnover rate $\left(\mathrm{V}_{\max }, \mathrm{CYP} 2 \mathrm{C} 19\right)$ for $S$-MBDB is nearly four times higher than for the $R$-form.

CYP2C19 showed the largest extent of enantioselectivity for demethylenation with a more than 30 fold higher affinity for the $S$-enantiomer. CYP2D6, CYP2B6, and CYP3A4 also showed marked enantioselectivity, with a 6,3 , and 2 fold higher affinity for the $S$-form of MBDB, respectively. Considering these findings along with the fact that demethylenation is the major metabolic step of MBDB metabolism in vivo, the different pharmacokinetic properties of the MBDB enantiomers are therefore most likely attributable to enantioselective demethylenation by different CYP isoforms. CYP2D6 should be most important in this context, because it accounts for more than two thirds of net clearance even at high substrate concentrations as compared to a maximum of $20 \%$ for CYP3A4. This must be considered when trying to estimate the time of ingestion from enantiomer ratios in plasma as proposed for e.g. MDMA [18,21], because the time course of such ratios may be considerably different 
in CYP2D6 poor metabolizers or in case of inhibition of CYP2D6 by MDMA or other co-

ingested drugs. In addition, it must be considered that correlation of the presented in vitro data with the in vivo situation is not straightforward, because in vivo DHMBB is further metabolized by $O$-methylation and/or glucuronidation/sulfation. Enantioselectivity of these phase II reactions might of course also influence the enantiomer ratios in plasma samples, especially those of DHMBB, but this has also to be proven experimentally.

Comparing the above mentioned findings with results previously published for MDMA [24], CYP2C19 seems to by critical for the enantioselective in vitro and in vivo metabolism of the presented methylenedioxy compounds available as secondary amines. A larger substituent next to the amine as in the case of MBDB seems to increase the affinity of the isoforms, especially CYP2C19, towards the $S$-enantiomer as one can see by the fact that the $R$ enantiomer of MBDB in racemic mixture is metabolized only in a very small amount. Furthermore, P450 isoforms seems to be, at least in part, responsible for the observed enantioselective in vivo metabolism of the ring substituted amphetamines.

\section{Acknowledgements}

The authors would like to thank Andrea E. Schwaninger, Katja Niesel, Armin A. Weber, and Carsten Schroeder for their assistance and helpful discussions. 


\section{References}

1. Van Aerts LAGJ, Mallaret M, Rigter H. N-methyl-1-(1,3-benzodioxol-5-yl)-2butanamine (MBDB): Its properties and possible risks. Addict Biol 2000;5:269-82.

2. Nichols DE, Hoffman AJ, Oberlender RA, Jacob P, Shulgin AT. Derivatives of 1-(1,3benzodioxol-5-yl)-2-butanamine: representatives of a novel therapeutic class. J Med Chem 1986;29:2009-15.

3. Oberlender R, Nichols DE. Drug discrimination studies with MDMA and amphetamine. Psychopharmacology (Berl) 1988;95:71-6.

4. Oberlender R, Nichols DE. (+)-N-methyl-1-(1,3-benzodioxol-5-yl)-2-butanamine as a discriminative stimulus in studies of 3,4-methylenedioxy-methamphetamine-like behavioral activity. J Pharmacol Exp Ther 1990;255:1098-106.

5. Nichols DE. Differences between the mechanism of action of MDMA, MBDB, and the classic hallucinogens. Identification of a new therapeutic class: entactogens. J Psychoactive Drugs 1986;18:305-13.

6. Steele TD, Nichols DE, Yim GK. Stereochemical effects of 3,4methylenedioxymethamphetamine (MDMA) and related amphetamine derivatives on inhibition of uptake of [3H]monoamines into synaptosomes from different regions of rat brain. Biochem Pharmacol 1987;36:2297-303.

7. Nichols DE, Oberlender R. Structure-activity relationships of MDMA-like substances. NIDA Res Monogr 1989;94:1-29.

8. Johnson MP, Nichols DE. Neurotoxic effects of the alpha-ethyl homologue of MDMA following subacute administration. Pharmacol Biochem Behav 1989;33:105-8.

9. Bai F, Lau SS, Monks TJ. Glutathione and N-acetylcysteine conjugates of alphamethyldopamine produce serotonergic neurotoxicity: possible role in methylenedioxyamphetamine-mediated neurotoxicity. Chem Res Toxicol $1999 ; 12: 1150-7$ 
10. Hiramatsu M, Kumagai Y, Unger SE, Cho AK. Metabolism of methylenedioxymethamphetamine: formation of dihydroxymethamphetamine and a quinone identified as its glutathione adduct. J Pharmacol Exp Ther 1990;254:521-7.

11. Miller RT, Lau SS, Monks TJ. 2,5-Bis-(glutathion-S-yl)-alpha-methyldopamine, a putative metabolite of (+/-)-3,4-methylenedioxyamphetamine, decreases brain serotonin concentrations. Eur J Pharmacol 1997;323:173-80.

12. de la Torre R, Farre M. Neurotoxicity of MDMA (ecstasy): the limitations of scaling from animals to humans. Trends Pharmacol Sci 2004;25:505-8.

13. Capela JP, Macedo C, Branco PS, Ferreira LM, Lobo AM, Fernandes E et al. Neurotoxicity mechanisms of thioether ecstasy metabolites. Neuroscience 2007;146:1743-57.

14. Maurer HH. On the metabolism and the toxicological analysis of methylenedioxyphenylalkylamine designer drugs by gas chromatography-mass spectrometry. Ther Drug Monit 1996;18:465-70.

15. Kronstrand R. Identification of N-methyl-1-(3,4-methylenedioxyphenyl)-2butanamine (MBDB) in urine from drug users. J Anal Toxicol 1996;20:512-6.

16. Kintz P. Excretion of MBDB and BDB in urine, saliva, and sweat following single oral administration. J Anal Toxicol 1997;21:570-5.

17. Maurer HH, Bickeboeller-Friedrich J, Kraemer T, Peters FT. Toxicokinetics and analytical toxicology of amphetamine-derived designer drugs ("Ecstasy"). Toxicol Lett 2000;112:133-42.

18. Fallon JK, Kicman AT, Henry JA, Milligan PJ, Cowan DA, Hutt AJ. Stereospecific analysis and enantiomeric disposition of 3, 4-methylenedioxymethamphetamine (Ecstasy) in humans. Clin Chem 1999;45:1058-69.

19. Kalant H. The pharmacology and toxicology of "ecstasy" (MDMA) and related drugs [review]. Can Med Assoc J 2001;165:917-28. 
20. Kraemer T, Maurer HH. Toxicokinetics of amphetamines: Metabolism and

toxicokinetic data of designer drugs, of amphetamine, methamphetamine and their $\mathrm{N}$ alkyl derivatives [review]. Ther Drug Monit 2002;24:277-89.

21. Peters FT, Samyn N, Wahl M, Kraemer T, de Boeck G, Maurer HH. Concentrations and Ratios of Amphetamine, Methamphetamine, MDA, MDMA, and MDEA Enantiomers determined in Plasma Samples From Clinical Toxicology and Driving Under the Influence of Drugs Cases by GC-NICI-MS. J Anal Toxicol 2003;27:552-9.

22. Peters FT, Samyn N, Lamers C, Riedel W, Kraemer T, de Boeck G et al. Drug Testing in Blood: Validated Negative-Ion Chemical Ionization Gas Chromatographic-Mass Spectrometric Assay for Enantioselective Determination of the Designer Drugs MDA, MDMA (Ecstasy) and MDEA and Its Application to Samples from a Controlled Study with MDMA. Clin Chem 2005;51:1811-22.

23. Pizarro N, Farre M, Pujadas M, Peiro AM, Roset PN, Joglar J et al. Stereochemical analysis of 3,4-methylenedioxymethamphetamine and its main metabolites in human samples including the catechol-type metabolite (3,4-dihydroxymethamphetamine). Drug Metab Dispos 2004;32:1001-7.

24. Meyer MR, Peters FT, Maurer HH. The Role of Human Hepatic Cytochrome P450 Isozymes in the Metabolism of Racemic MDMA and its Enantiomers. Drug Metab Dispos 2008;36:2345-54.

25. Lin LY, Di Stefano EW, Schmitz DA, Hsu L, Ellis SW, Lennard MS et al. Oxidation of methamphetamine and methylenedioxymethamphetamine by CYP2D6. Drug Metab Dispos 1997;25:1059-64.

26. Kreth K, Kovar K, Schwab M, Zanger UM. Identification of the human cytochromes P450 involved in the oxidative metabolism of "Ecstasy"-related designer drugs. Biochem Pharmacol 2000;59:1563-71. 
27. Tucker GT, Lennard MS, Ellis SW, Woods HF, Cho AK, Lin LY et al. The demethylenation of methylenedioxymethamphetamine ("ecstasy") by debrisoquine hydroxylase (CYP2D6). Biochem Pharmacol 1994;47:1151-6.

28. Brunnenberg M, Kovar KA. Stereospecific analysis of ecstasy-like N-ethyl-3,4methylenedioxyamphetamine and its metabolites in humans. J Chromatogr B Biomed Sci Appl 2001;751:9-18.

29. Buechler J, Schwab M, Mikus G, Fischer B, Hermle L, Marx C et al. Enantioselective quantitation of the ecstasy compound (R)- and (S)-N-ethyl-3,4methylenedioxyamphetamine and its major metabolites in human plasma and urine. $\mathrm{J}$ Chromatogr B Analyt Technol Biomed Life Sci 2003;793:207-22.

30. Peters FT, Kraemer T, Maurer HH. Drug testing in blood: validated negative-ion chemical ionization gas chromatographic-mass spectrometric assay for determination of amphetamine and methamphetamine enantiomers and its application to toxicology cases. Clin Chem 2002;48:1472-85.

31. Sauer C, Peters FT, Schwaninger AE, Meyer MR, Maurer HH. Identification of Cytochrome P450 Enzymes Involved in the Metabolism of the Designer Drugs $\mathrm{N}-(1-$ Phenylcyclohexyl)-3-ethoxypropanamine (PCEPA) and N-(1-Phenylcyclohexyl)-3methoxypropanamine (PCMPA). Chem Res Toxicol 2008;21:1949-55.

32. Clarke SE. In vitro assessment of human cytochrome P450. Xenobiotica 1998;28:1167-202.

33. Crespi CL, Miller VP. The use of heterologously expressed drug metabolizing enzymes-state of the art and prospects for the future. Pharmacol Ther 1999;84:121-31.

34. Venkatakrishnan K, von Moltke LL, Court M.H., Harmatz JS, Crespi CL, Greenblatt DJ. Comparison between cytochrome P450 (CYP) content and relative activity approaches to scaling from cDNA-expressed CYPs to human liver microsomes: ratios of accessory proteins as sources of discrepancies between the approaches. Drug Metab Dispos 2000;28:1493-504. 
35. Grime K, Riley RJ. The impact of in vitro binding on in vitro-in vivo extrapolations, projections of metabolic clearance and clinical drug-drug interactions. Curr Drug Metab 2006;7:251-64.

36. Newton DJ, Wang RW, Lu AY. Cytochrome P450 inhibitors. Evaluation of specificities in the in vitro metabolism of therapeutic agents by human liver microsomes. Drug Metab Dispos 1995;23:154-8.

37. Guengerich FP. Human Cytochrome P450 Enzymes. In: Ortiz-de-Montellano PR, editor. Cytochrome P450 - Structure, Mechanism, and Biochemistry. 3rd ed. New York: Kluwer Academic/Plenum Publishers, 2005. p. 377-530.

38. Crespi CL. Xenobiotic-metabolizing human cells as tools for pharmacological and toxicological research. In: Testa B, Meyer UA, editors. Advances in Drug Research. 26 ed. London: Academic Press, 1995. p. 179-235.

39. Carter N, Rutty GN, Milroy CM, Forrest AR. Deaths associated with MBDB misuse. Int J Legal Med 2000;113:168-70.

40. Rothe M, Pragst F, Spiegel K, Harrach T, Fischer K, Kunkel J. Hair concentrations and self-reported abuse history of 20 amphetamine and ecstasy users. Forensic Sci Int 1997;89:111-28.

41. Heydari A, Yeo KR, Lennard MS, Ellis SW, Tucker GT, Rostami-Hodjegan A. Mechanism-based inactivation of CYP2D6 by methylenedioxymethamphetamine. Drug Metab Dispos 2004;32:1213-7. 


\section{Legends to the Figures}

Fig. 1. - The two main metabolic steps of $R$ - and $S$-MBDB leading to the formation of the corresponding enantiomers of 1,2-dihydroxy-4-[2-(methylamino)butyl]benzene (DHMBB) and 3,4-methylenedioxybutanamin (BDB).

Fig. 2. - Typical mass fragmentograms of ions $m / z 430$ for DHBA and $m / z 780$ for DHMBB of an incubation mixture (CYP2C19) of racemic MBDB (A), $R$-MBDB (B), and $S$-MBDB (C) after derivatization.

Fig. 3. - Michaelis-Menten plots for BDB (left) and DHMBB (right) formation catalyzed by CYP2B6 (3A) and CYP2C19 (3B) and Michaelis-Menten plots for DHMBB formation catalyzed by CYP2D6 (3C left), CYP1A2 (3C right), and CYP3A4 (3D). Data points represent means and ranges (error bars) of duplicate measurements. The solid curves represent formation of $R$-BDB/R-DHMBB from racemic $\mathrm{MBDB}$ (upper part) and $R$-MBDB (lower part). The broken curves represent formation of $S$-BDB/S-DHMBB from racemic MBDB (upper part) and $S$-MBDB (lower part).

Fig. 4. - Plots of calculated total net clearance (\%) vs. substrate concentration for the $\mathrm{N}$ demethylation plus demethylenation.

Fig. 5. - Effect of the chemical inhibitor quinidine (closed column), $3 \mu \mathrm{mol} / \mathrm{L}$ (CYP2D6) on demethylenation in incubation mixtures containing $5 \mu \mathrm{mol} / \mathrm{L}$ of $R, S-, R$ - or $S$-MBDB. Metabolite formation of the control incubations (open column) was set to $100 \%$. Each bar represents the mean of six incubations \pm standard error of the mean. $(* * * p<0.005)$. 
Fig. 6. - Eadie-Hofstee plots of CYP2B6 for $S$-MBDB and CYP3A4 for racemic MBDB and

1

2

3

4

5

6

7

8

9

10

11

12

13

14

15

16

17

18

19

20

21

22

23

24

25

26

27

28

29

30

31

32

33

34

35

36

37

38

39

40

41

42

43

44

45

46

47

48

49

50

51

52

53

54

55

56

57

58

59

60

61

62

63

64

65

$S$-MBDB (demethylenation) indicating biphasic kinetics. 
Table 1

Kinetic Data for the Two Main Metabolic Steps of MBDB

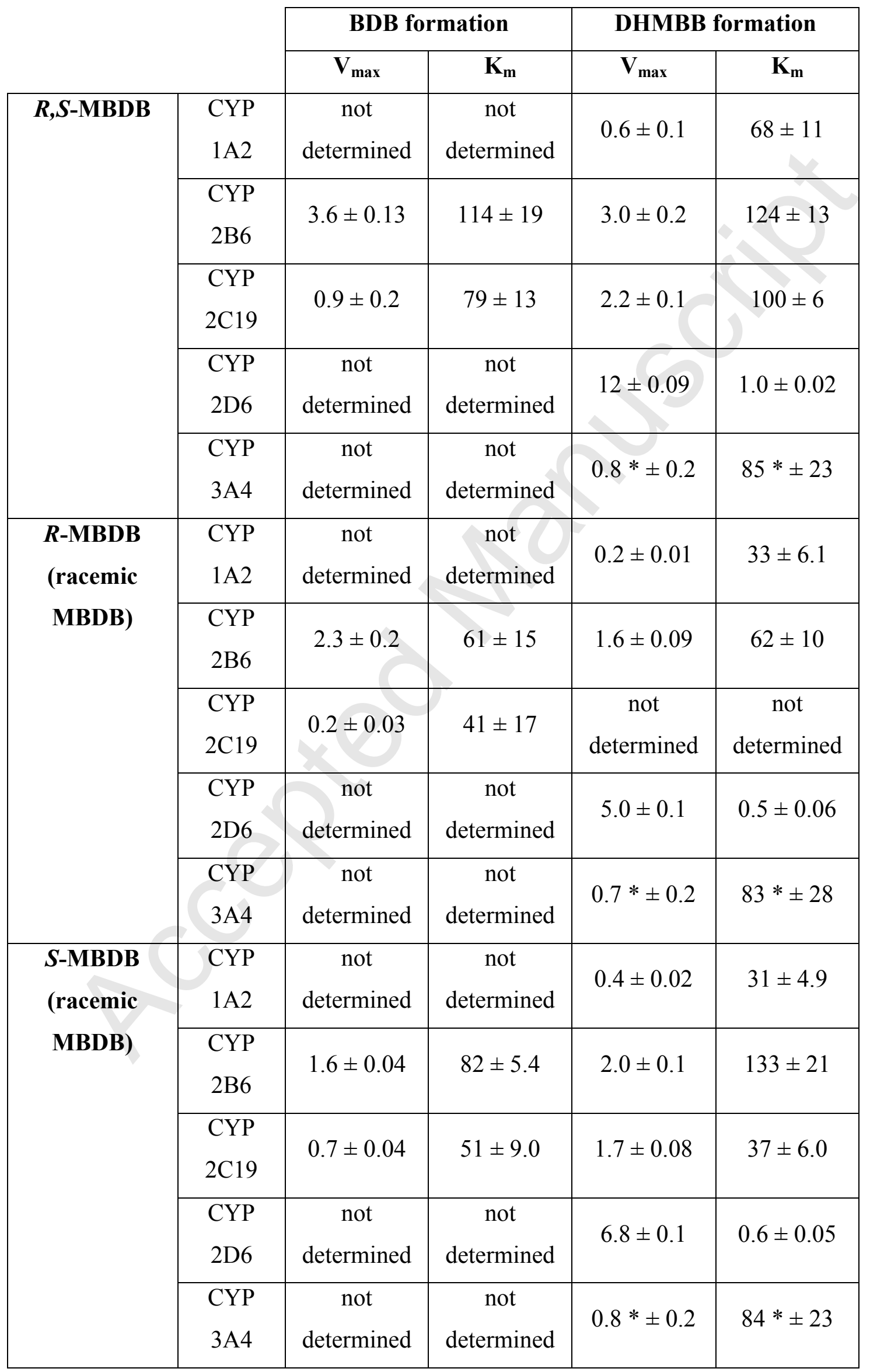




\begin{tabular}{|c|c|c|c|c|c|}
\hline \multirow{5}{*}{$\begin{array}{c}R \text {-MBDB } \\
\text { (single } \\
\text { enantiomer) }\end{array}$} & $\begin{array}{l}\text { CYP } \\
1 \mathrm{~A} 2\end{array}$ & $\begin{array}{c}\text { not } \\
\text { determined }\end{array}$ & $\begin{array}{c}\text { not } \\
\text { determined }\end{array}$ & $0.5 \pm 0.02$ & $121 \pm 15$ \\
\hline & $\begin{array}{l}\text { CYP } \\
2 B 6\end{array}$ & $2.5 \pm 0.06$ & $138 \pm 10$ & $3.3 \pm 0.09$ & $83 \pm 8.0$ \\
\hline & $\begin{array}{l}\text { CYP } \\
2 \mathrm{C} 19\end{array}$ & $0.2 \pm 0.01$ & $46 \pm 6.0$ & $1.0 \pm 0.03$ & $85 \pm 9.0$ \\
\hline & $\begin{array}{l}\text { CYP } \\
\text { 2D6 }\end{array}$ & $\begin{array}{c}\text { not } \\
\text { determined }\end{array}$ & $\begin{array}{c}\text { not } \\
\text { determined }\end{array}$ & $11 \pm 0.2$ & $2.2 \pm 0.2$ \\
\hline & $\begin{array}{l}\text { CYP } \\
3 \mathrm{~A} 4\end{array}$ & $\begin{array}{c}\text { not } \\
\text { determined }\end{array}$ & $\begin{array}{c}\text { not } \\
\text { determined }\end{array}$ & $0.7 \pm 0.02$ & $88 \pm 9$ \\
\hline \multirow{5}{*}{$\begin{array}{c}S \text {-MBDB } \\
\text { (single } \\
\text { enantiomer) }\end{array}$} & $\begin{array}{l}\text { CYP } \\
1 \mathrm{~A} 2\end{array}$ & $\begin{array}{c}\text { not } \\
\text { determined }\end{array}$ & $\begin{array}{c}\text { not } \\
\text { determined }\end{array}$ & $0.6 \pm 0.02$ & $131 \pm 16$ \\
\hline & $\begin{array}{l}\text { CYP } \\
2 B 6\end{array}$ & $0.7 \pm 0.03$ & $119 \pm 16$ & $0.2 * \pm 0.07$ & $56 * \pm 14$ \\
\hline & $\begin{array}{l}\text { CYP } \\
2 \mathrm{C} 19\end{array}$ & $0.3 \pm 0.02$ & $73 \pm 18$ & $0.6 \pm 0.02$ & $2.6 \pm 0.02$ \\
\hline & $\begin{array}{l}\text { CYP } \\
\text { 2D6 }\end{array}$ & $\begin{array}{c}\text { not } \\
\text { determined }\end{array}$ & $\begin{array}{c}\text { not } \\
\text { determined }\end{array}$ & $6.3 \pm 0.1$ & $0.4 \pm 0.05$ \\
\hline & $\begin{array}{l}\text { CYP } \\
3 \mathrm{~A} 4\end{array}$ & $\begin{array}{c}\text { not } \\
\text { determined }\end{array}$ & $\begin{array}{c}\text { not } \\
\text { determined }\end{array}$ & $0.4 * \pm 0.06$ & $28 * \pm 8.0$ \\
\hline
\end{tabular}

units are: $\mathrm{V}_{\max }, \mathrm{pmol} / \mathrm{min} / \mathrm{pmol} ; \mathrm{K}_{\mathrm{m}}, \mu \mathrm{mol} / \mathrm{L}$

* $\mathrm{V}_{\max 1}$ and $\mathrm{K}_{\mathrm{m} 1}$ 


\section{Figure 1}
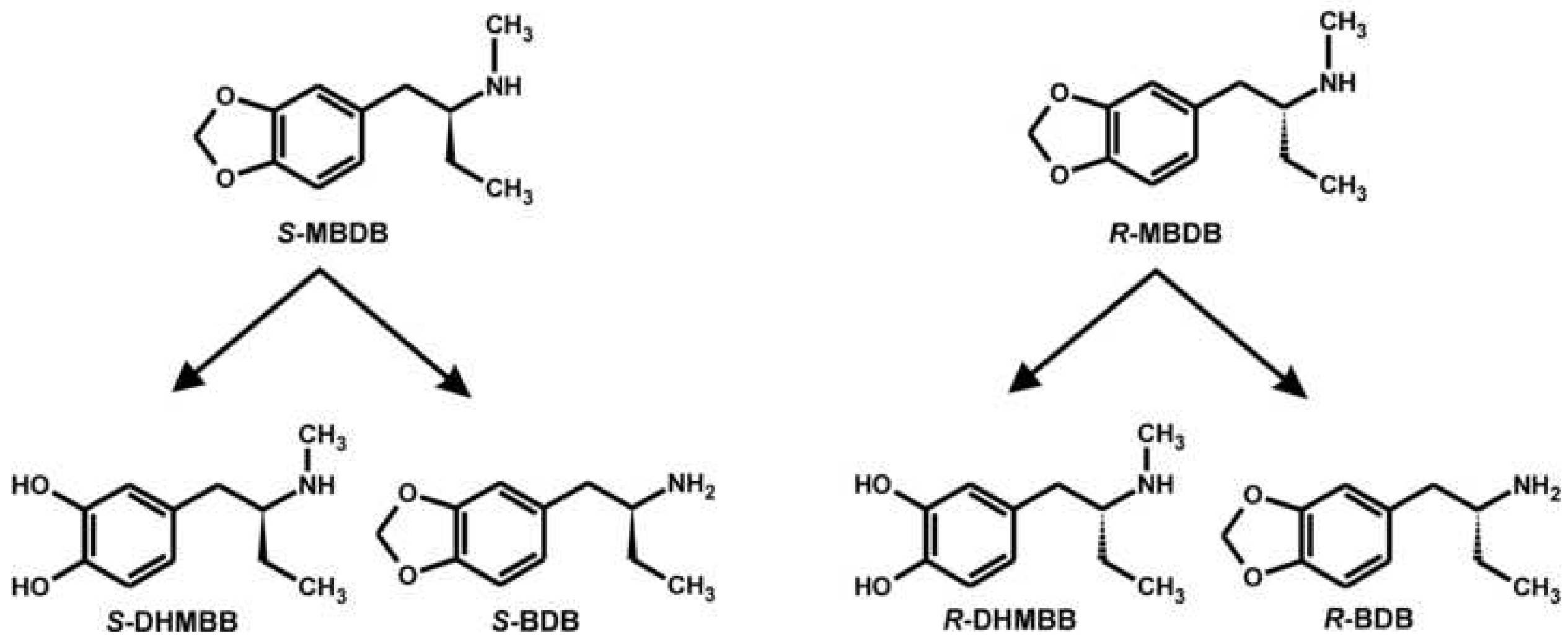
Figure 2
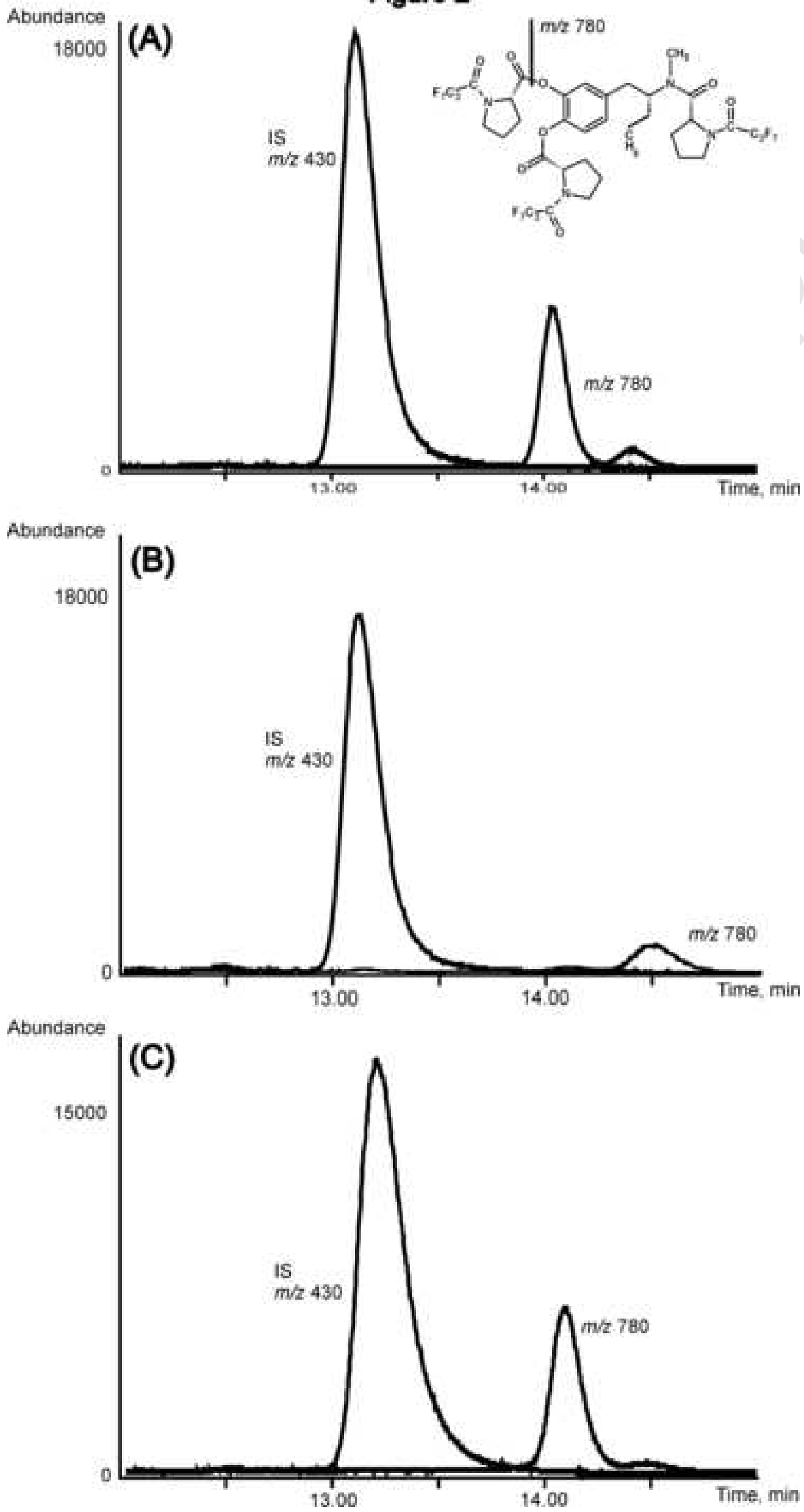
Flgure 3A

\section{CYP2B6}
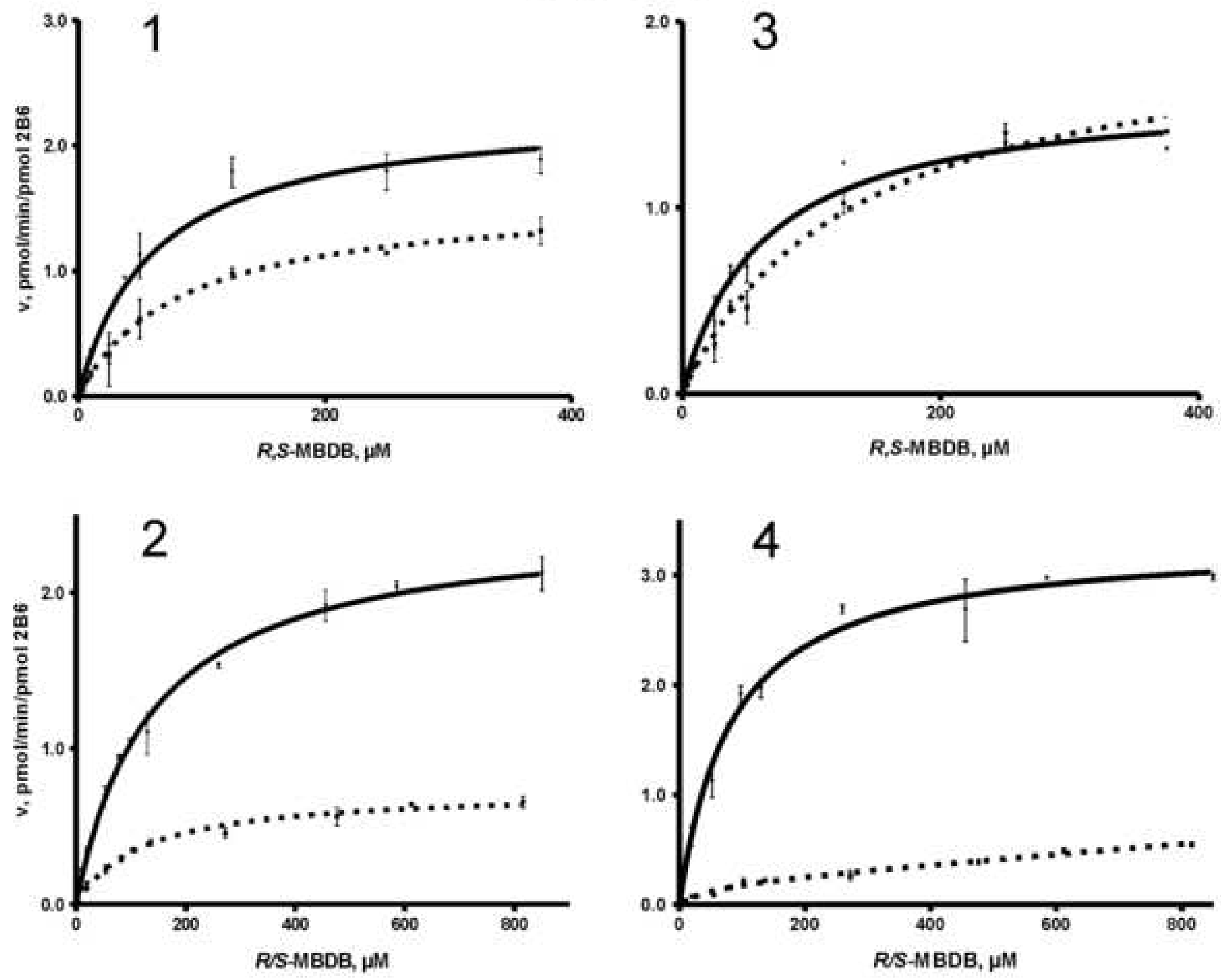

rage $2 y$ or 35 


\section{CYP2C19}
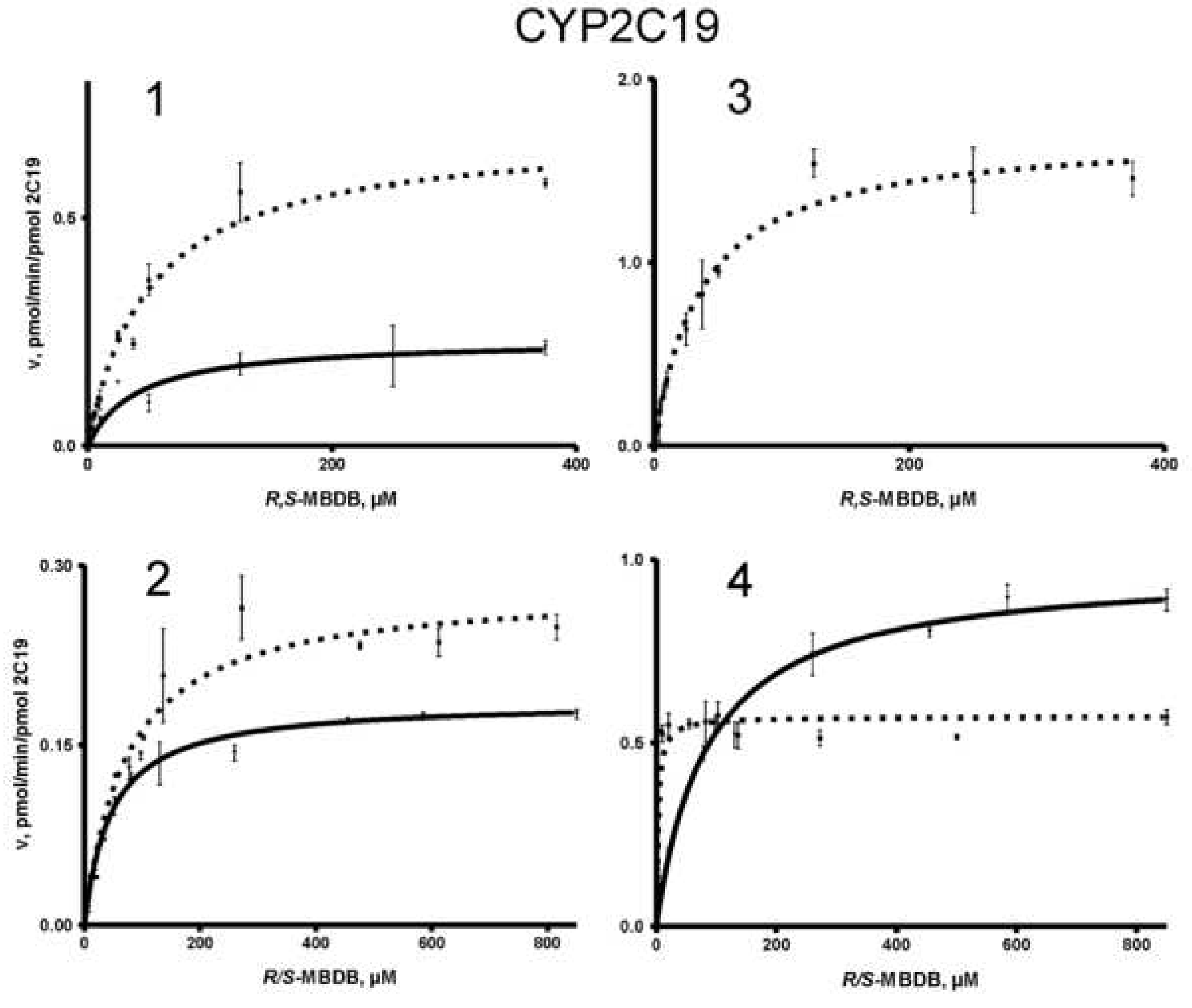

rage 30 or 35

Figure 3B 


\section{CYP2D6/1A2}
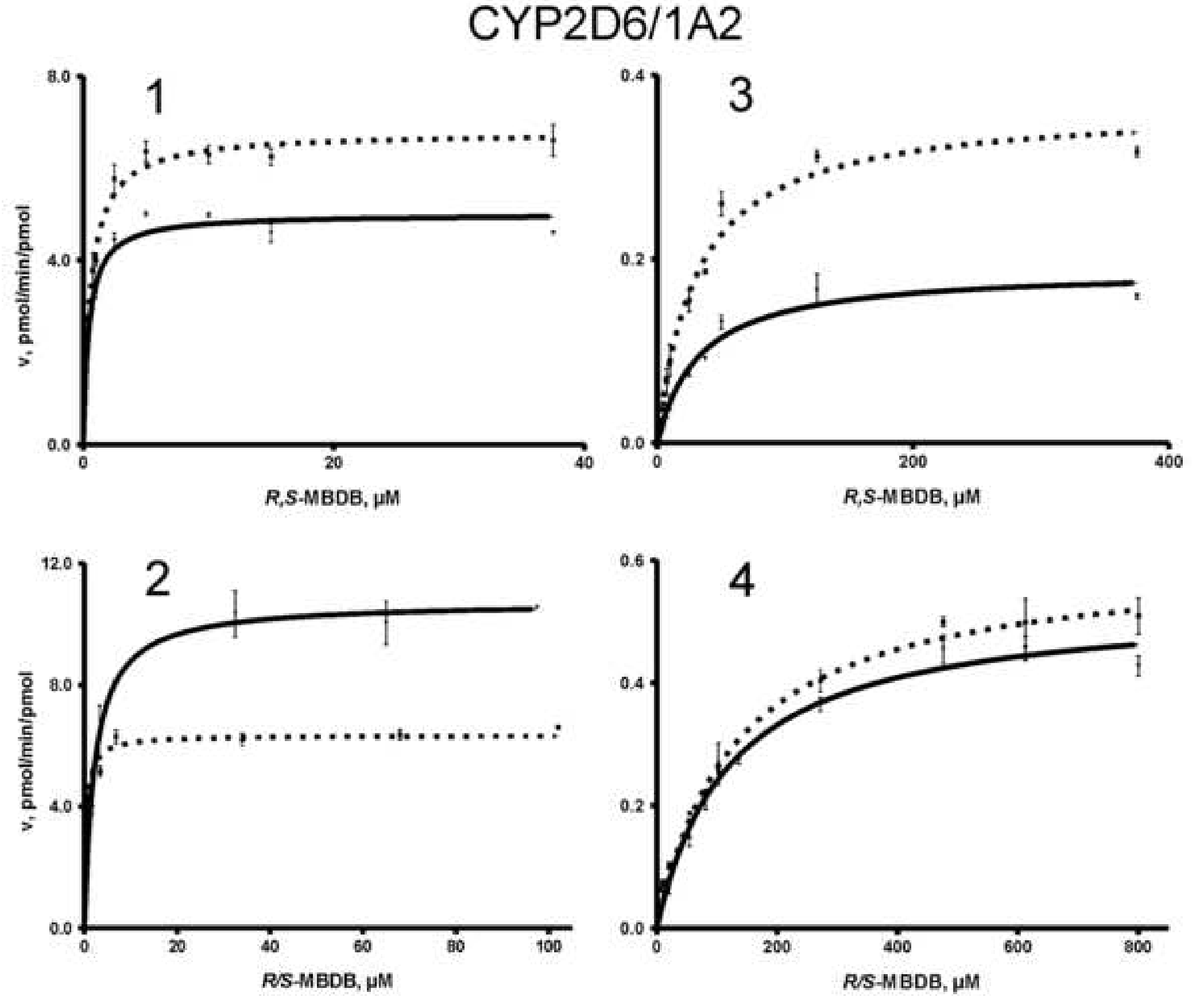

rage 31 о 35

\section{Figure 3C}

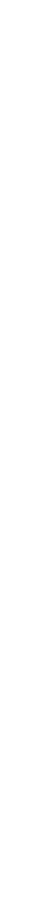




\section{Flgure 3D}

\section{CYP3A4}
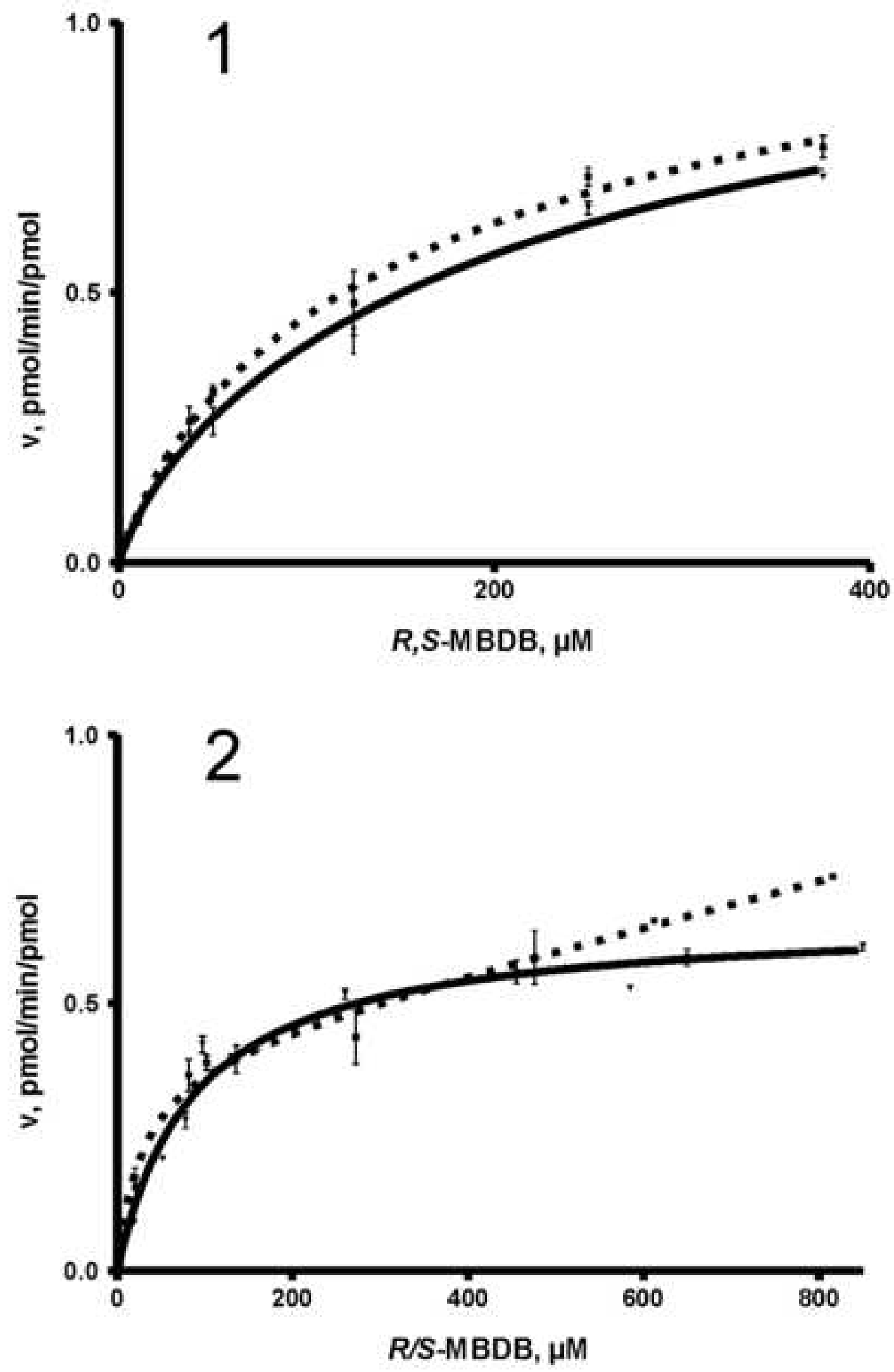

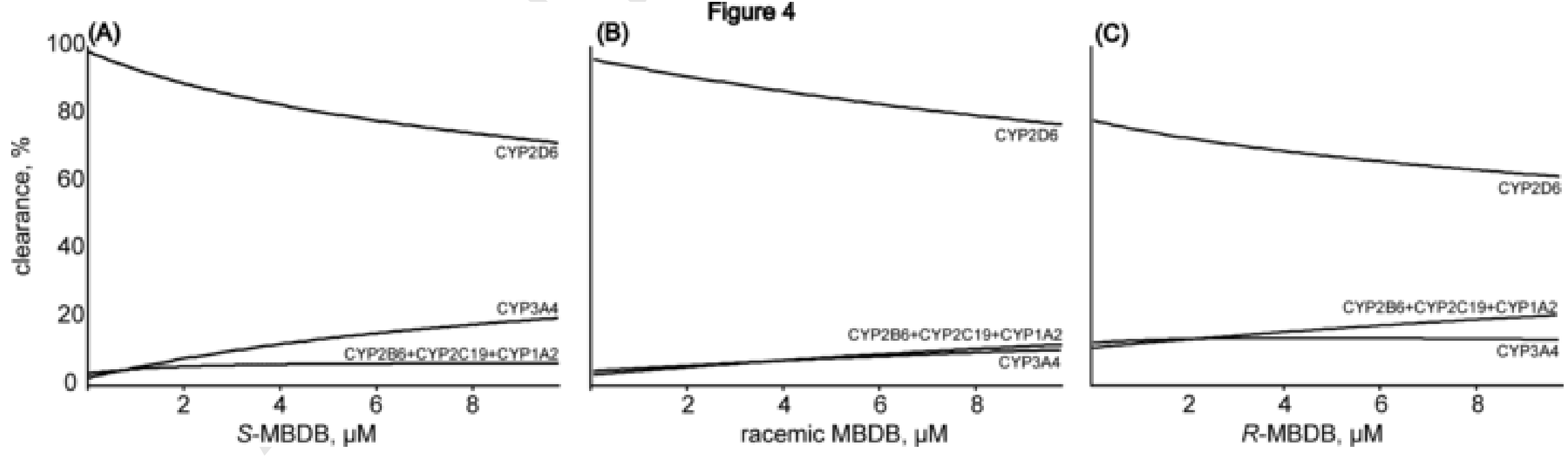


\section{Flgure 5}

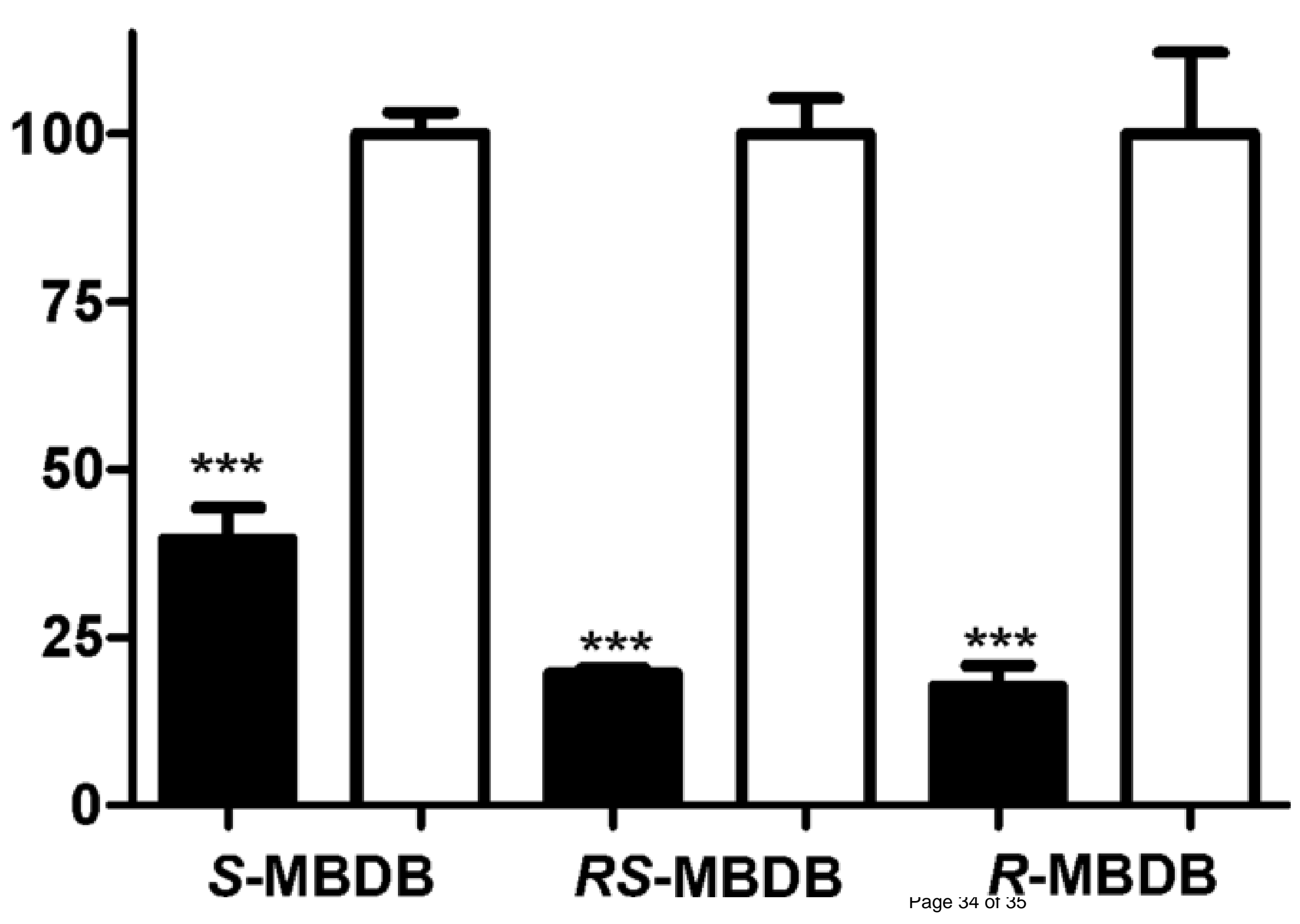




\section{Fgure 6}

CYP3A4, S-DHMBB formation

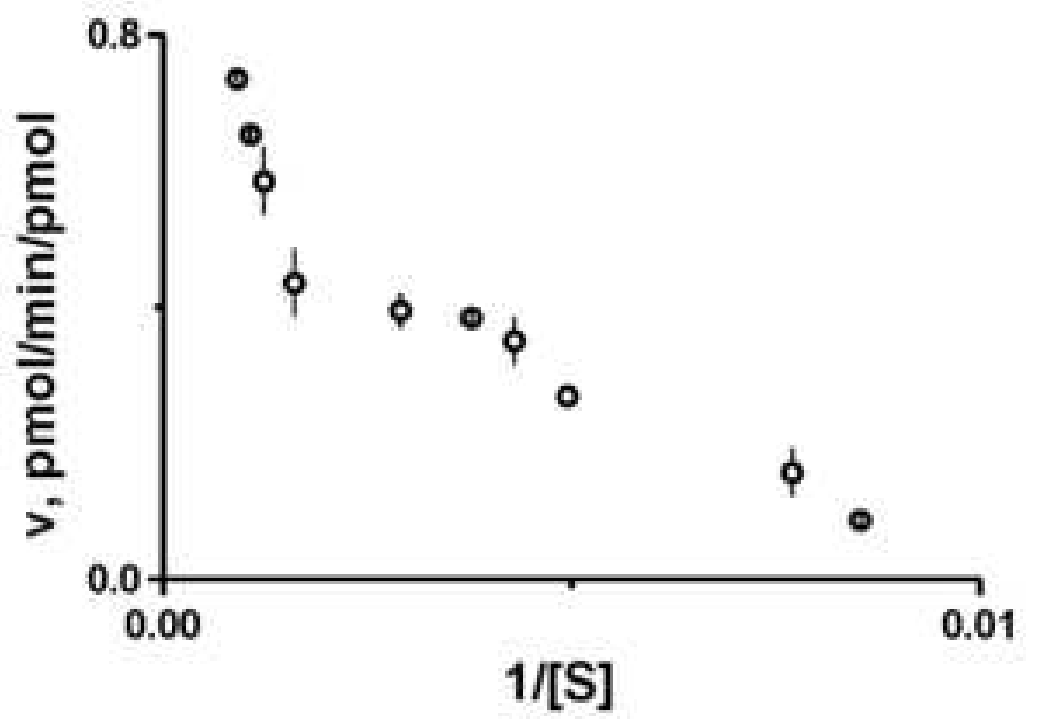

CYP2B6, S-DHMBB formation

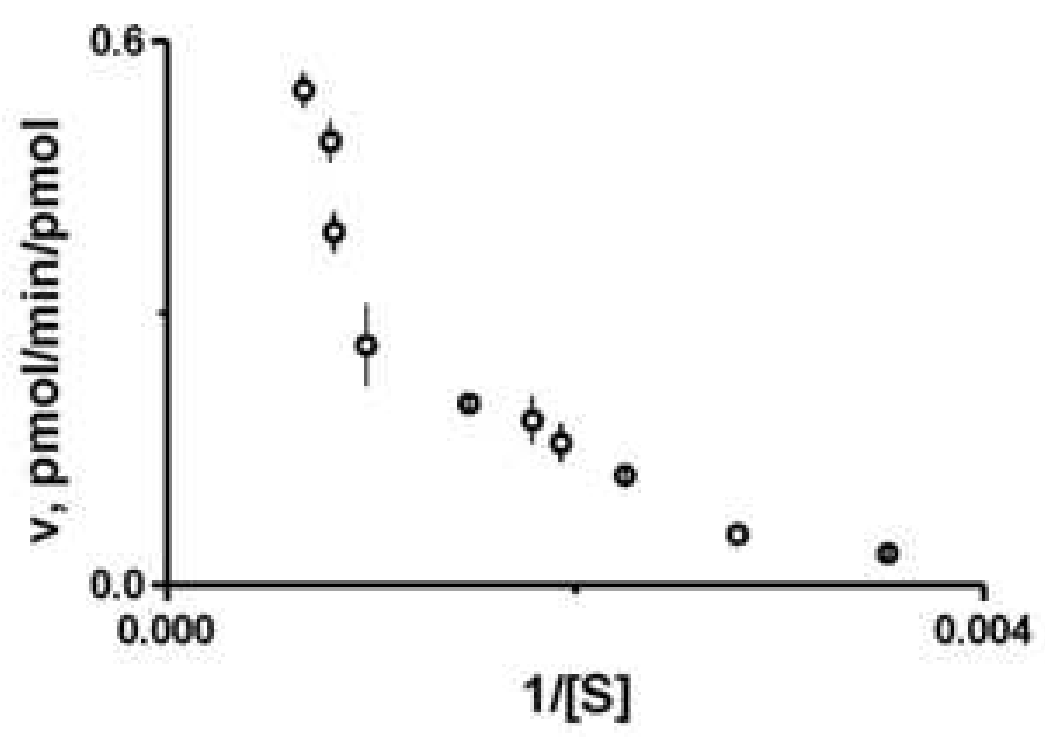

CYP3A4, racemic DHMBB formation

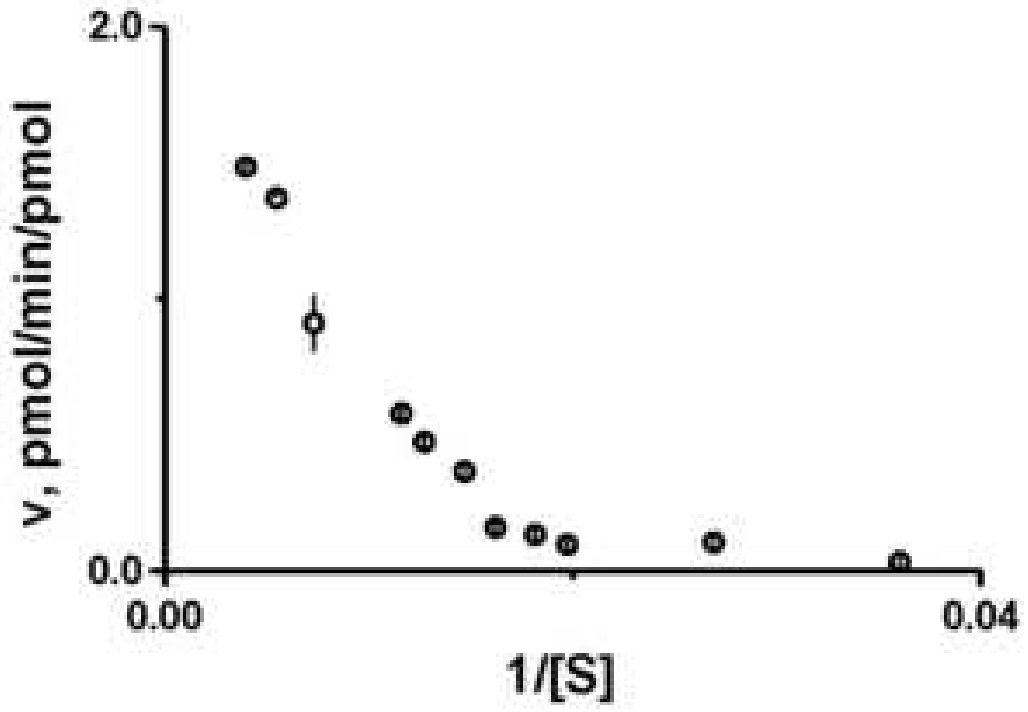

